\title{
Implementation and Technical Testing of a Robot for Future Use in Patients Care (Covid-19)
}

\section{Implementación y Pruebas Técnicas de un Robot para Uso Futuro en la Atención Hospitalaria (Covid-19)}

\author{
E. M. Rico-Mesa', J. G. Barrientos-Gómez², S. Correa-Zapata', V. A. Acevedo-Urrego², P. A. Palacios-Correa', \\ V. A. Álvarez-Tobón'², J. C. Londoño-Lopera', Y. A. Aguilar-Pérez², Y. S. Jaramillo-Munera', E. A. Torres-Silva², \\ C. A. Vergara-Crismatt', B. S. Jiménez-Franco², L. Tobón-Ospina', J. S. Parada-Zuluaga², J. E. Goez-Mora', \\ J. S. Tamayo-Zapata', J. D. Arismendy-Pulgarín \\ 'Servicio Nacional de Aprendizaje de Colombia SENA \\ ²Clínica Universitaria Bolivariana
}

\begin{abstract}
The present paper describes a mobile robot's construction with telemedicine functions built by a multi-disciplinary team of engineers and doctors. During this process, a technical test was applied to the Robot, employing medical care simulations. The technical test was carried out in a hospital in Medellin - Colombia, which verifies the robot behaviors in its displacement, stability, and temperature measurement. The hospital environment's robot viability has been studied, presenting the positive and negative aspects through a Strengths, Weaknesses, Opportunities, and Threats (SWOT) analysis matrix and its targeting through action strategies. In the future, the robotic system will work in health institutions to accompany patients and professionals in the crisis caused by the SARS-CoV-2 virus (COVID-19).
\end{abstract}




\section{RESUMEN}

El presente artículo describe la construcción de un robot móvil con funciones de telemedicina construida por un equipo multidisciplinario de ingenieros y médicos. Durante este proceso, se aplicó una prueba técnica al Robot, empleando simulaciones de atención médica. La prueba técnica, que consistió en verificar los comportamientos del robot en su desplazamiento, estabilidad y medición de temperatura, se realizó en un hospital de Medellín - Colombia. Se ha estudiado la viabilidad del robot en el entorno hospitalario, presentando los aspectos positivos y negativos a través de una matriz de análisis de Fortalezas, Debilidades, Oportunidades y Amenazas (FODA) y su focalización a través de estrategias de acción. En el futuro, el robot trabajará en instituciones de salud para acompañar a pacientes y profesionales en la crisis provocada por el virus SARS-CoV-2 (COVID-19).

PALABRAS CLAVE: Robot asistente médico; Telemedicina;Evaluación técnica; SARS-CoV-2;Matriz FODA

\section{Corresponding author}

TO: Edgar Mario Rico Mesa

INSTITUTION: Servicio Nacional de Aprendizaje de

Colombia SENA

ADDRESS: Calle 57 \#8-69, Barrio Chapinero Central,

C. P. 110231, Bogotá, Cundinamarca, Colombia

E-MAIL: emrico@sena.edu.co

\section{Received:}

19 September 2021

Accepted:

18 March 2021 


\section{INTRODUCTION}

In the latest months of 2019 was known about an infectious disease, which is a consequence of the SARS$\mathrm{CoV}-2$ virus. This disease was detected in Wuhan's (China) city and caused great concern in both the scientific community and the World Health Organization (WHO). The virus spread rapidly throughout the world, so, on March 11, 2020, the world health organization (WHO) declared the disease associated with this virus as a pandemic ${ }^{[1]}{ }^{[2]}$. In the actual context, a huge portion of the world population has been confined; the most affected countries are the USA, China, and Italy; nevertheless, as of this article's writing, Latin America is projected as the new epicenter of the pandemic ${ }^{[3]}$. Several companies and research groups have converged on finding solutions for the health sector to mitigate the crisis. The absence of medical equipment and supplies is currently projected as the main problem affecting the countries fighting against Covid-19 ${ }^{[4]}$. The first line of care is composed of doctors and internists. Those people are at a high level of exposure to the virus, and they must ensure the least possible interaction with infected patients. Considering the above, the adaptation of technological tools that support basic care processes, such as anamnesis, is essential. The proposed solutions must have a good cost-benefit ratio for the health sector, knowing that it must allocate a few resources to the crisis attention. The number of infected health staff is increasing. This reflects the difficulties in prevention, even when biosecurity standards are implemented. Long working days can generate skin injuries from the continuous use of protective elements ${ }^{[5]}$, which could cause physicians to make mistakes unintentionally in handling their protection. Infections among health staff have critical consequences for the health system since the hospitals and clinics' response capacity is considerably reduced when their personnel is in confinement, as has occurred in China and Italy ${ }^{[6]}$. Considering the above, robotic systems' contribution is important as tools for health staff to perform specific functions that minimize the risk of infection ${ }^{[7]}{ }^{[8]}$. Several databases were consulted (Scopus, IEEE, Science Direct, etc.) to find jobs related to remote medical assistance, which are being used in the current SARS-CoV-2 virus pandemic. Francesco et al. ${ }^{[9]}$ presented multi-agent architecture. It is directed to intelligent medical care and can select patients supervised by the doctor on duty. Geng et al. ${ }^{[10]}$ implemented a telerobotic system for remote care in patient isolation rooms; the robot plays two roles in the interaction with patients: teleoperation and telepresence. Koppu et al. ${ }^{[1]}$ proposed a model of early detection of the disease using a predictive model based on deep learning. This paper describes the implementation of a mobile robot operated by a health institution's medical staff to perform specific telemedicine functions; in this process, a follow up of the hospital attention during the COVID 19 pandemic is made. The paper is organized as follows methods and materials, results and discussion, conclusions, and ethical statement.

\section{MATERIALS AND METHODS}

The robotic system was developed according to the needs of "Clínica Universitaria Bolivariana (CUB)" which also addresses some general problems in the health sector. In March 2020, the most suitable materials, electrical, electronic, and mechanical components were selected from "Servicio Nacional de Aprendizaje (SENA)" and the Colombian national market. As for the methodology used, this is an experimental applied research project. Figure 1 shows the methodological framework followed in the development of this project.

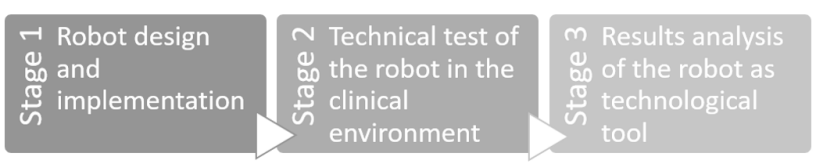

FIGURE 1. Methodological framework.

\section{Stage 1: Robot design and implementation}

In April 2020, a robotic system was designed and implemented for remote medical care (telemedicine). The criteria for the operation of the robot was proposed by "Bolivarian University Clinic (CUB)." For this 
reason, GACIPE (Research Group in Automation, Industrial Communications, Pedagogy and Alternative Energies) -a SENA's research group-, conceived a system composed of a mobile robot controlled by a "Raspberry Pi 4" board and control system using a graphic user interface implemented on a laptop, based on the following criteria:

- The materials and the structure must contribute to asepsis and sterilization:

The robot's structural cover, support design and construction took the asepsis and sterilization conditions into account. Therefore, a design in the Solid works software was made and this was implemented in 3D printers, whose fundamental characteristic is surfaced flat and smooth curves without any abrupt relief. This type of design intends to facilitate cleaning. The PLA material was chosen because it allows making quick prototyping parts. The mechanical (acceptable tensile strength and modulus of elasticity), physical (adequate resistance to moisture and grease, and good electrical and thermal insulator) properties [12] are suitable for the function that the robot fulfills. The body is developed in aluminum to avoid some oxidation using CNC machines in its implementation.

- Access confined spaces like regular hospital rooms:

In the mechanical design of the structure, the minimum dimension of the robot of 130x40x40 $\mathrm{cm}$ was determined, taking into account the ease of moving in confined spaces. Also, the distribution of the weights of the different components and modules of the robot were defined to have stability in movement and avoid probabilities of overturning according to the zero moment point criterion. Simulations evaluated the robot structure in the NX software.
The robot's electrical and electronic mechanism's design and development use a kinematic model of mobile robotics for four Omnidirectional wheels. This model was designed and implemented to allow stable locomotion of the robot to overcome obstacles in reduced space. For the robot's motion control (kinematics), the controller is a "Raspberry pi 4 ".

- Communicate the patient with the doctor and family remotely:

In the design and development of the interactive module of the robot, the Ubuntu 18.04 operative system was implemented on the robot's development board ("Raspberry pi 4") and the controller (laptop) in which communication is incorporated by the network (WiFi) to establish remote communication using the high-performance free software video call application called Jitsi Meet as interaction platform.

- Measure vital signs of the patient and show them online to the doctor:

The module selected for the body temperature measurement, the GY906 module, has the MLX90614 sensor. The data obtained by the module are processed and sent via WiFi from the robot to the graphical interface for the doctor to see them online. The set-up and calibration of the temperature for its processing in the robot (carried out by "Raspberry pi 4") was obtained based on the commercial product MCH-370.

- $\quad$ The quality of the audiovisual system must be of high definition:

In the interactive module, the components of the audiovisual system used to execute high definition video calls were defined, consisting of 
the high-performance (720p) webcam (image and audio for the doctor) and a high resolution (1080p) capacitive touch of 13.3 inches (Image and audio for the patient).

Once all the criteria proposed by the Bolivarian University Clinic were met, the assembly and tuning of the robot's operation in the clinic was carried out. Therefore, when the robot was complete, a series of functional tests were carried out, in terms of movement in confined spaces, communication between patient and doctor, and verification of vital signs data obtained from patients and battery data to verify the robot's energy autonomy.

\section{Stage 2: Technical test of the robot in the clinical environment}

In May 2020, the operation of the robot started in the hospital's facilities. At this time, the design of the intervention plan of the robot in the CUB is determined. In principle, training sessions were held with the clinic's medical staff with the team's accompaniment who developed the robot. This activity aims to appropriate the technological tool and know the doctors' and nurses' perceptions about the robot's advantages and disadvantages. Once this process has been completed, a technical test of equipment operation in clinical service without patients was carried out. This to a medical assistance simulation (pilot test) corresponds to verify aspects of the technological tool's use and handling. During this test, the technical team worked with medical staff and identified barriers and limitations that should be corrected to facilitate future interaction with patients.

\section{Stage3: Results analysis of the robot as a technological tool}

In June 2020, a report about the technical performance was made, which describes the health staff's perceptions. The report was focused on analyzing the response of the robotic system as a tool to support patient care. The prototype was technically verified and analyzed from a SWOT matrix, taking into account the pilot test. The elements that should be verified in an eventual usability test with patients in a high complexity health institution were identified.

\section{RESULTS AND DISCUSSION}

\section{Results}

The project has three main phases in which the transition from the robot to the clinical application is focused.

Robotic system implementation: The robot's development began with meetings among the GACIPE group and the CUB to determine its functions. The defined function is related to telemedicine; the main function was to communicate the health staff and the family with COVID patients. The robot's role established the design, modeling, and construction of the robot's structure and body. The chassis and supports were made of aluminum to avoid oxidation generated by the hospital environment and disinfection procedures (Figure 2A). The bodywork was made of PLA material to make the robot's cleaning easier (Figure 2B) to have a strict aseptic procedure. Also, the robot's weight was an important factor to facilitate its maneuverability within the clinical environment. These aspects were taken into account for the robot's mechanical component (see Figure 2C). The electrical, electronic, and telecommunication modules are developed, considering the mobile robot's conditions and function in the clinic. The motors and wheels have been selected according to the robot's projected weight $(25 \mathrm{~kg})$ and the surface type for its displacement. The power system is considered according to the technical characteristics of the motors (60w). The batteries are selected according to the autonomy required in the clinic (at least 
8 hours). The communication established for audio and video (interactive module) is used through Wi-Fi. However, the transmission of measurement and control data is implemented through radiofrequency $(\mathrm{RF})$. The displacement control, monitoring of variables, and transmission of the video call are developed through a high-performance processing system called "Raspberry pi 4".

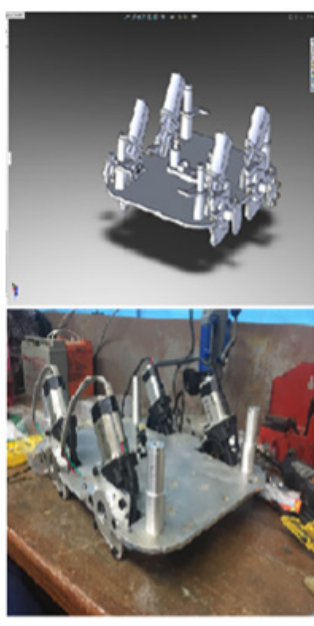

a)

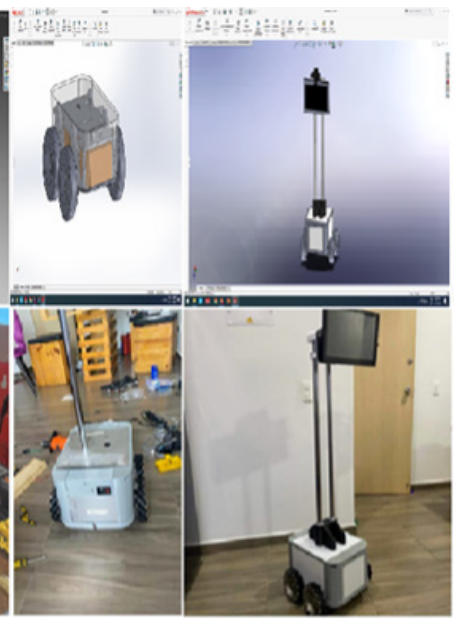

c)
FIGURE 2. Implementation of the body, chassis and structure of the robot. A) Design and construction of the robot chassis. B) Design and development of the robot body. C) Complete mechanical conformation.

The general description of the operation for the system is presented in Figure 3.

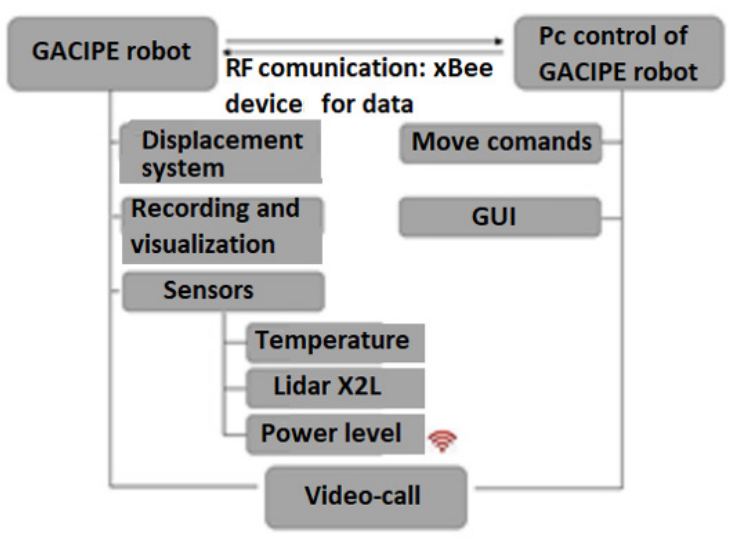

FIGURE 3. Robot processing operating scheme.

\section{Design elements required for robot testing:}

- Kinematics of robot movement:

The medical assistant robot was designed with omnidirectional wheels, which provide great flexibility in the load movement's movements. It is also very versatile in small spaces. Due to its shape, the kinematic study is more complex. The configuration of the robot can be seen on its own platform in Figure 4.

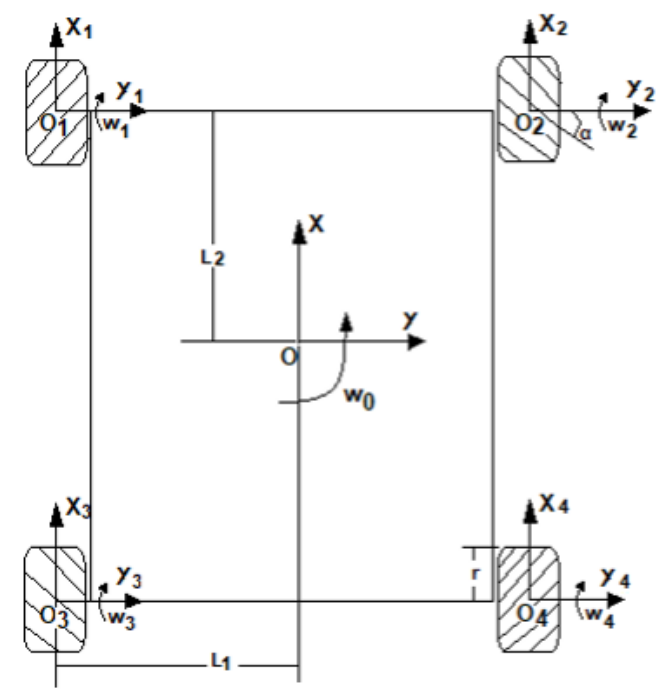

FIGURE 4. Platform top view.

The goal is to know the speed of each tire in terms of linear speeds ${ }^{[13]}$. It is established:

$$
\begin{gathered}
v_{w}=\left[\begin{array}{llll}
w_{1} & w_{2} & w_{3} & w_{4}
\end{array}\right]^{T} \\
v_{o}=\left[\begin{array}{lll}
v_{x} & v_{y} & w_{o}
\end{array}\right]^{T}
\end{gathered}
$$

Where:

w1, w2, w3, w4 corresponds to the angular velocity value of each wheel.

$v_{x} v_{y} w_{o}$ are the velocity in the $\mathrm{x}, \mathrm{z}$, axis, and angular velocity around the robot's $O$ point. 
From the kinematic analysis ${ }^{[14]}$, it is obtained that:

$$
v_{w}=J(\alpha) v_{o}
$$

With:

$\alpha$ is the angle that determines the direction of each of the rollers to the horizontal.

$$
J(\alpha)=\frac{1}{r}\left[\begin{array}{ccc}
1 & \frac{1}{\tan \alpha} & -\frac{L_{1} \tan \alpha+L_{2}}{\tan \alpha} \\
1 & -\frac{1}{\tan \alpha} & \frac{L_{1} \tan \alpha+L_{2}}{\tan \alpha} \\
1 & \frac{1}{\tan \alpha} & -\frac{L_{1} \tan \alpha+L_{2}}{\tan \alpha} \\
1 & -\frac{1}{\tan \alpha} & \frac{L_{1} \tan \alpha+L_{2}}{\tan \alpha}
\end{array}\right]
$$

Being:

$r$ the radius of the wheel.

In this way, it is possible to manipulate the dynamics of the robot's movement ${ }^{[15]}$.

\section{- Temperature sensor calibration:}

The GY906 module that comes with the MLX90614 sensor signal conditioning is a sensor which measures temperature without contact with objects; it is suitable for medical applications since its measurement error in the range 36-39 degrees Celsius is \pm 0.1 degrees centigrade, allowing to obtain relevant measurements on the human body. The calculation of the measurement is configured according to the technical data sheet of the MLX90614. Afterwards, the sensor was compared with a commercial IR temperature measurement product called $\mathrm{MCH}-370$ (TR), whose function is to measure the head's front (product endorsed by "Instituto Nacional de Vigilancia de Medicamentos y Alimentos" INVIMA - Colombia). For the GY906 (TD) calibra- tion, a series of measurements between 1 and 3 centimeters were made, taking the commercial product as a reference. For this, 5 measurements every $1 \mathrm{~cm}$ were taken; the results are presented in terms of error (TR-TD) and distance (see Figure 5).

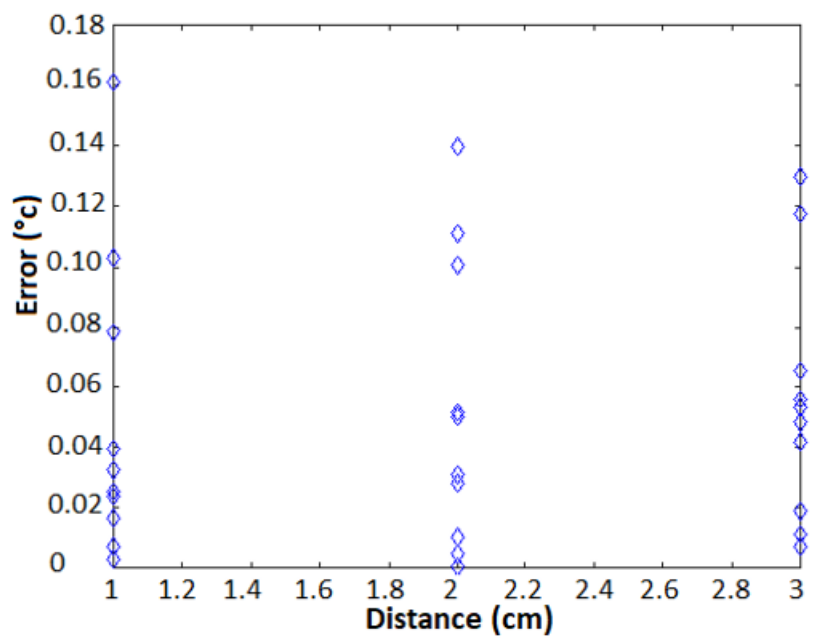

FIGURE 5. Graphic representation of the temperature error from the frontal area of the head measured by GY906.

In these tests, an adequate response has been found for the GY906 module, observing the measurement error in most data below 0.1 degrees centigrade.

- Robot control:

Additionally, to control the movement of the robot, the balance of the robot was taken into account at all times based on the criterion of the zero moment point (ZMP) raised by Vukobratovic exposed in articulated robots [16] [17] and mobile robots ${ }^{[18]}{ }^{[19]}$, it is calculated for each point of support (wheel), the center of mass, rotational moment of inertia, angular acceleration, acceleration in the three coordinate axes, taking into account that each wheel has an independent actuator (motor). The $\mathrm{x}, \mathrm{y}$ coordinate is found 
with these data, and with equations 5 and 6 that correspond to the zero-moment point (ZMP) shown in Figure 6. If the coordinates provided are within the polygon armed by the support points, then the system is stable, and the probability of overturning is minimal.

$$
\begin{aligned}
& x_{Z M P}=\left(\sum_{i=1}^{n} m_{i}\left(\ddot{z}_{i}+g\right) x_{i}-\right. \\
& \left.\sum_{i=1}^{n}\left(\ddot{\Omega}_{i y} I_{i y}\right)\right) / \sum_{i=1}^{n} m_{i}\left(\ddot{z}_{i}+g\right) \\
& y_{Z M P}=\left(\sum_{i=1}^{n} m_{i}\left(\ddot{z}_{i}+g\right) y_{i}-\right. \\
& \left.\sum_{i=1}^{n}\left(\ddot{\Omega}_{i x} I_{i x}\right)\right) / \sum_{i=1}^{n} m_{i}\left(\ddot{z}_{i}+g\right)
\end{aligned}
$$

such that

$x_{i}, y_{i}, z_{i}$ are the coordinates of the Center of Mass (CoM) of each wheel

$\ddot{x}_{i}, \ddot{y}_{i}, \ddot{z}_{i}$ is the acceleration of the robotic system in $\mathrm{z}, \mathrm{y}, \mathrm{x}$

$\ddot{\Omega}_{i}$ is the angular acceleration

$I_{i}$ is the rotational inertia

$\mathrm{g}$ is the acceleration of gravity

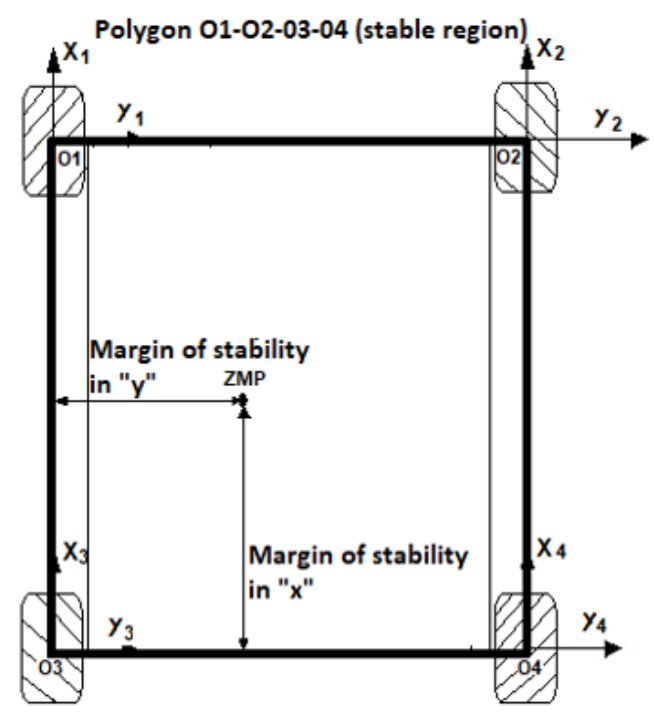

FIGURE 6. Robot balance.

\section{- Robot simulation:}

The robot was configured in Solidworks software and simulated in NX based on the design criteria in kinematics and stability. The test used focuses on the robot, starting from rest moving forward a distance of approximately 1 meter, and ending up again at rest. The robot's simulation environment moving on a flat surface is presented below (see Figure 7).

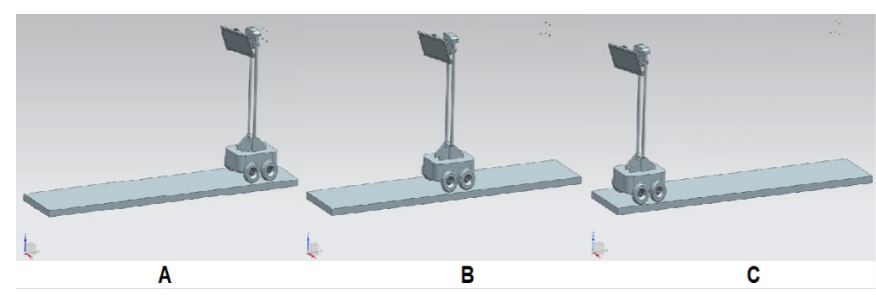

FIGURE 7. Reproduction of the robot movement in software. A) At the beginning of the road. B) In the middle of the road. C) At the end of the road.

According to Figure 7, the robot is in a virtual environment moving forward on a flat surface shown through three moments (beginning, middle, and end). In this case, we wanted to analyze the behavior of the robot in its kinematics and stability.

Starting from the case shown in Figure 7B, theoretical and simulated stability and kinematic analysis are carried out, the results of which are established in table 1 , taking into account that $\alpha=$ $45^{\circ}, v_{x}$ prom $=0.377$ meters $/$ second, $\mathrm{r}=0.075$ meters.

According to Table 1, the linear and angular velocity has been obtained with the modeled and simulated kinematics. With it, the acceleration and torque used in each motor have been determined. These data allowed us to feed the calculations of the zero-point moment. The results 
obtained indicate that the acceleration value is at the stability limit. Therefore, if they are exceeded, there is a risk of overturning in the " $\mathrm{x}$ " direction. Considering the above information, it was defined to do the control taking into account the kinematics of movement of the robot counts an acceleration ramp of three seconds, having as maximum acceleration the maximum value determined in the simulated case $\left(0.045 \mathrm{mt} / \mathrm{seg}^{2}\right)$.

TABLE 1. Results of the model and simulation

\begin{tabular}{|c|c|c|c|c|c|c|}
\hline \multirow{2}{*}{ Mode } & \multirow{2}{*}{ 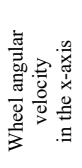 } & \multirow{2}{*}{ 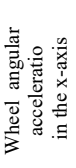 } & \multicolumn{2}{|c|}{$\begin{array}{c}\text { Zero } \\
\text { moment point }\end{array}$} & \multicolumn{2}{|c|}{$\begin{array}{c}\text { Margin } \\
\text { of stability }\end{array}$} \\
\hline & & & $\mathrm{x}$ & $\mathrm{y}$ & $\mathrm{x}$ & $\mathrm{y}$ \\
\hline Theoretical & 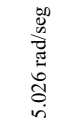 & 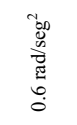 & $\begin{array}{l}\vec{\Xi} \\
\frac{\Xi}{\dot{\Xi}} \\
\dot{1}\end{array}$ & 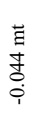 & ڤे & $\begin{array}{l}\exists \\
\end{array}$ \\
\hline Simulated & 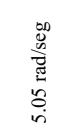 & 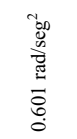 & 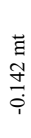 & $\begin{array}{l}\vec{\Xi} \\
\text { D } \\
\text { J } \\
\dot{0} \\
\dot{0}\end{array}$ & $\stackrel{\infty}{8}$ & 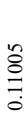 \\
\hline
\end{tabular}

Control interface: To operate the robot was developed a user interface in Python using the Tkinter module. The equipment's functions could be considered as telepresence and telemonitoring. Telepresence consists of the robot's remote control using a series of commands activated by the computer keyboard. For the proper handling, the robot was equipped with an audiovisual system that is the voice and image of medical personnel assisting the patient. Telemonitoring consists of the remote measurement of the temperature activated by a command immersed in a virtual button of the user interface. In the upper part of the robot, is incorporated a temperature sensor. It measures the variable at $3 \mathrm{~cm}$ from the patient. The current status of the batteries' energy storage is also being checked at all times; allowing us to determine the robot's energy autonomy (Figure 8).

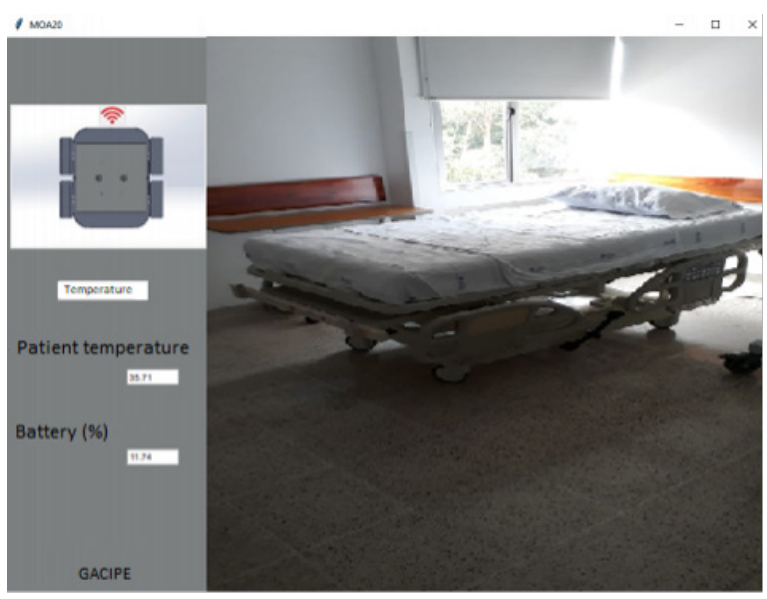

FIGURE 8. Graphical User Interface.

Once the mechanical module, the electronic module, and the graphic interface had been consolidated, the robot's integral operations technical tests were carried out in the laboratory. In the robot operation, the precision of the robot's movements in reduced spaces as verified, the environment monitoring (laser scanner), the measuring of vital signs (temperature), the behavior of the batteries to determine energy autonomy and energy storage management were checked The behavior of the structure was also verified when the cleaning and disinfection process was done. Likewise simulated medical visits to test the link with the WiFi network and the communication between the patient and the health staff were conducted (Figure 9). Finally, the robot's size was determined as follows: $40 \mathrm{~cm}$ wide, $40 \mathrm{~cm}$ long, and $1.30 \mathrm{~cm}$ high.

\section{Verification of the robot's behavior in the clinic:} The CUB was in charge of monitoring and handling the robot; during a technical test, this test was developed respecting the internal regulations of the institution. Additionally, the techni- 


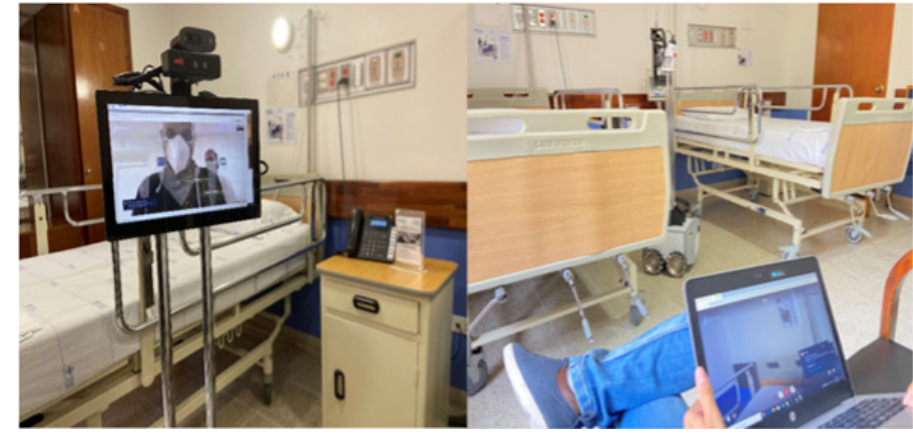

a)

b)

FIGURE 9. Adaptation of the robot to the operating conditions in the clinic.

A) Robot RAM. B) User interface.

cal team accompany this tests during the process. It is important to indicate that difficulties were observed with the temperature sensor due to the location, so it was disabled. After that, in the process of appropriation and handling of the robot in the clinic a pilot test. was defined The pilot test is developed, taking into account two stages or moments, which are presented below.

\section{WARNINGS}

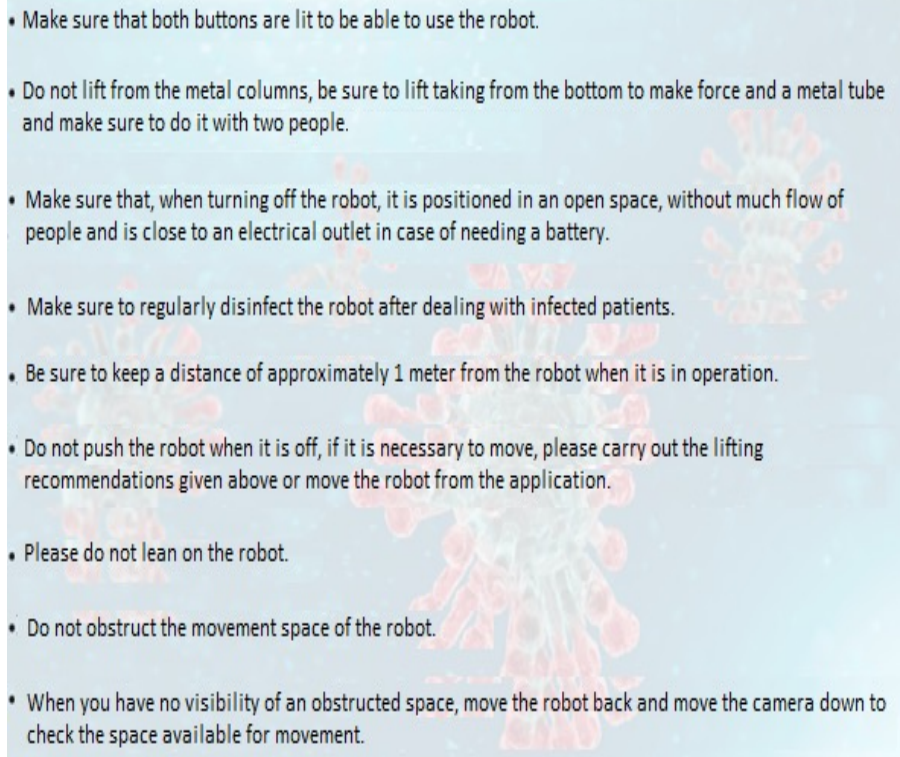

FIGURE 10. Warning instructions.
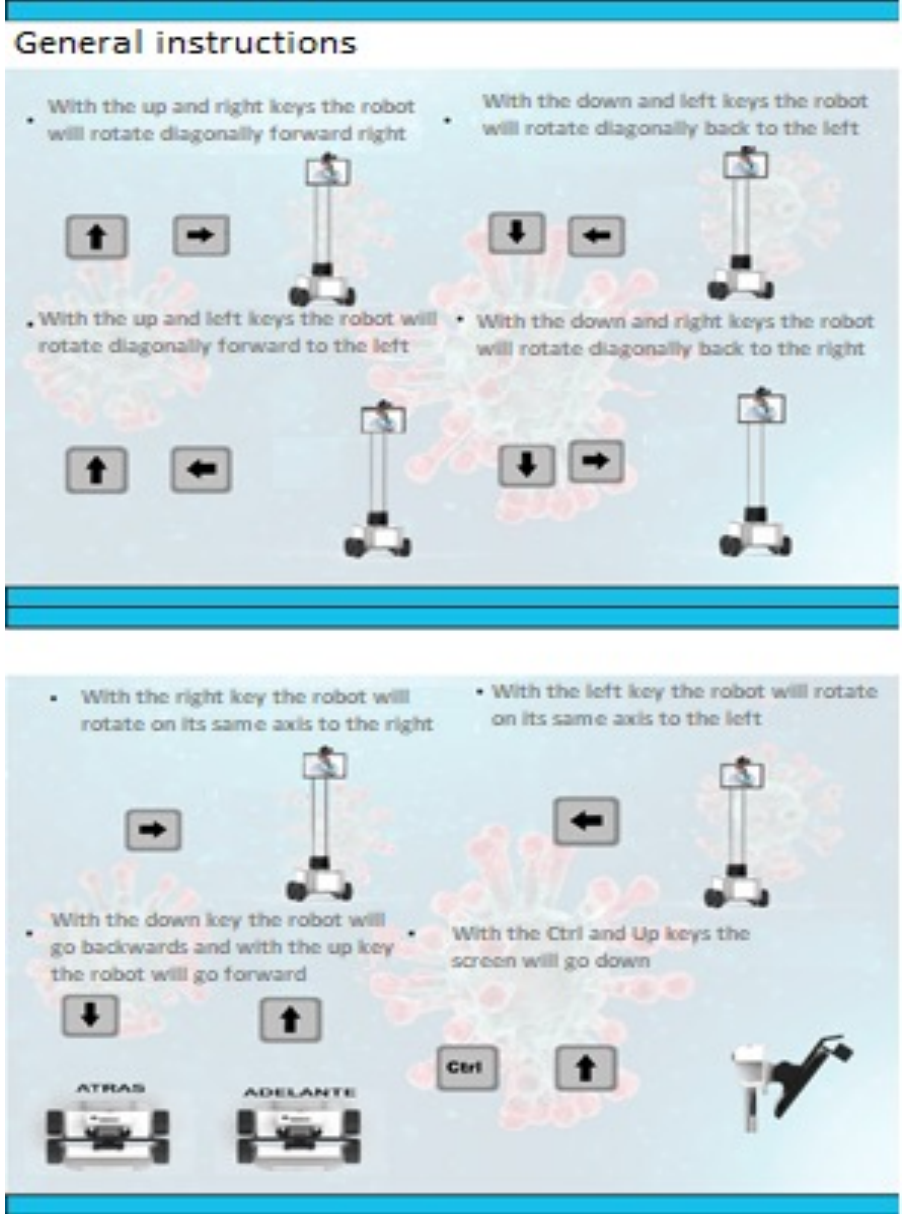

FIGURE 11. General instructions.

Training of health staff: The first stage consisted of the robot's introduction to the health staff, related to the robot's handling. In that process, the user manual and the technical card were introduced. The user manual is a document elaborated with graphic components in which the basic operation of the robot is summarized. The indications presented in the manual are: Warnings, general instructions, interface instructions, start-up, and shut-down process. There are a series of instructions about actions to avoid in the warnings, which might cause damage or trouble in the robot's operation (Figure 10).

The general instructions show the operating instructions for moving the robot using the control system's keyboard (Figure 11). 
On the other hand, interface instructions show the special functions incorporated in virtual buttons. These functions are focused on communication and telemonitoring of temperature and energy data (Figure 12).

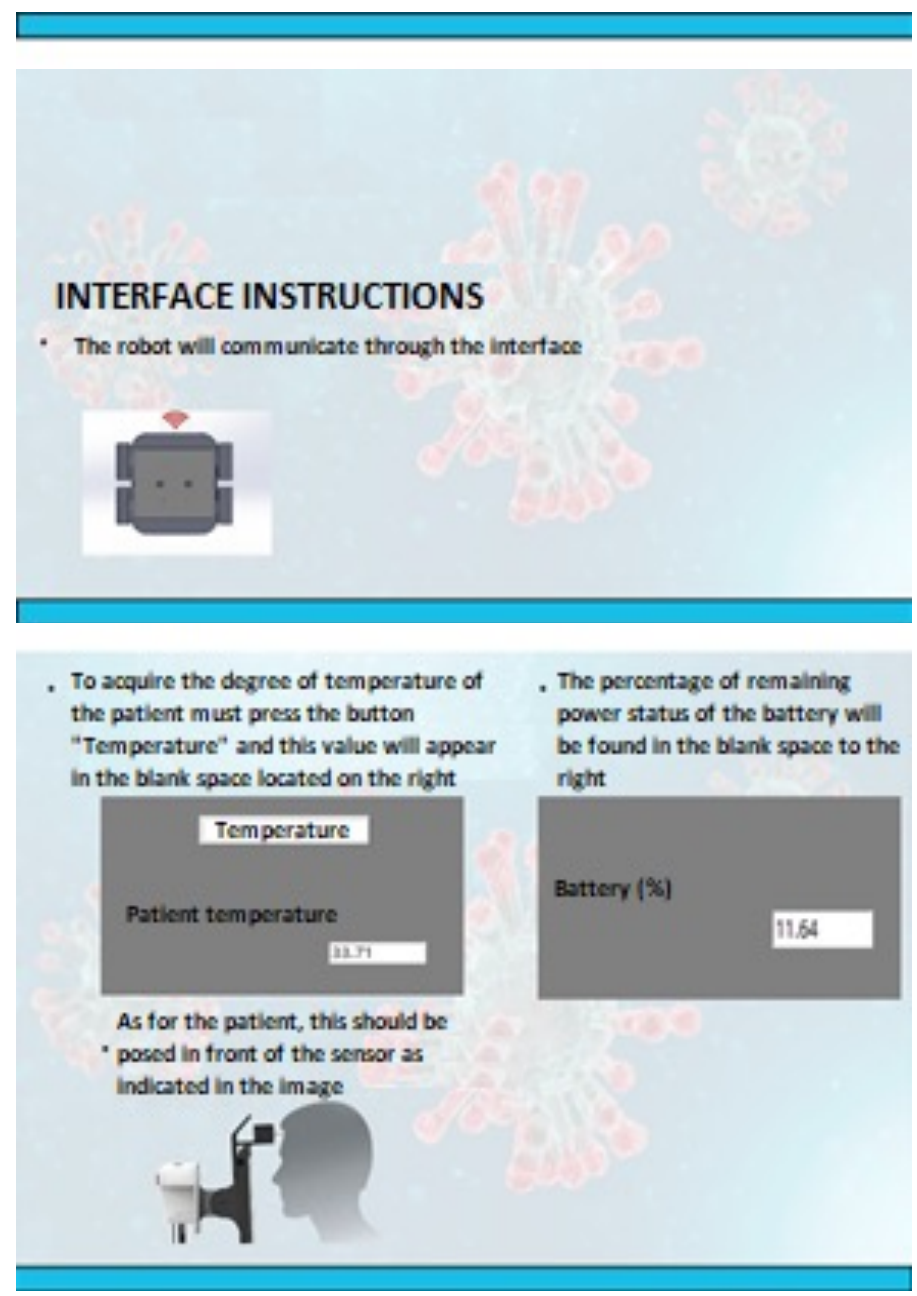

FIGURE 12. GUI instructions.

The technical data sheet shows the operational limitations of the robot. Thus, the technical data sheet consists of mechanical, electrical, electronic, and system technical data (see Table 2).

The robot's technical test: The second stage consisted of patient-free tests for robot training and were conducted with the health staff according to the clinic's plan. This allowed the health staff to become familiar with the robot's handling in clin-
TABLE 2. Robot technical specifications

\begin{tabular}{|c|c|}
\hline \multicolumn{2}{|c|}{ Datasheet GACIPE-MOA20 } \\
\hline \multicolumn{2}{|c|}{ Conceived Use } \\
\hline Robot Medical Assistant & Patient Care Robotics \\
\hline \multicolumn{2}{|c|}{ Dimensions } \\
\hline HxLxW & $130 \times 40 \times 40 \mathrm{~cm}$ \\
\hline Weight & $25 \mathrm{~kg}$ \\
\hline \multicolumn{2}{|c|}{ Color } \\
\hline RAL 7001 & Grey silver \\
\hline \multicolumn{2}{|c|}{ Loading capacity } \\
\hline $\begin{array}{l}\text { Maximum load } \\
\text { on the platform }\end{array}$ & $50 \mathrm{~kg}$ \\
\hline \multicolumn{2}{|c|}{ Speed and performance } \\
\hline Autonomy & 8 hours \\
\hline Maximum speed & $0.38 \mathrm{mt} / \mathrm{seg}$ \\
\hline Turning radius & $30 \mathrm{~cm}$ \\
\hline Positioning accuracy & $1 \mathrm{~cm}$ \\
\hline \multicolumn{2}{|c|}{ Power supply } \\
\hline Battery & Gel 24v 20A \\
\hline Internal charger & $\begin{array}{l}\text { Input } 110 \mathrm{v} 0.28 \mathrm{~A} \\
60 \mathrm{hz} \text { Output } 12 \mathrm{v} 8 \mathrm{~A}\end{array}$ \\
\hline \multicolumn{2}{|c|}{ Environment } \\
\hline Ambient temperature range & $0-50$ \\
\hline IP protection class & IP20 \\
\hline \multicolumn{2}{|c|}{ Communication } \\
\hline WiFi & $\begin{array}{c}\text { IEEE } 802.11 . \mathrm{b} / \mathrm{g} / \mathrm{n} / \mathrm{ac} \\
2.4 / 5 \mathrm{GHz}\end{array}$ \\
\hline $\mathrm{RF}$ & $\begin{array}{c}\text { IEEE } 802.15 .42 .4 \mathrm{Ghz} \\
250 \mathrm{Kbps}\end{array}$ \\
\hline $\mathrm{I} / \mathrm{O}$ & HDMI, USB y Ethernet \\
\hline \multicolumn{2}{|c|}{ Sensor } \\
\hline Laser scanner (Lidar) & $\begin{array}{l}360 \text { visual protection } \\
\text { around the robot }\end{array}$ \\
\hline \multicolumn{2}{|c|}{ Interface } \\
\hline \multicolumn{2}{|c|}{ Screen } \\
\hline Dimensions $(\mathrm{HxLxW})$ & $20.79 \times 32.95 \times 2.25 \mathrm{~cm}$ \\
\hline Resolution & 1920x1080 Lines \\
\hline Type & Capacitive Touch Size 13.3" \\
\hline \multicolumn{2}{|c|}{ Camera } \\
\hline Resolution & $720 \mathrm{p} / 30 \mathrm{fps}$ \\
\hline \multicolumn{2}{|c|}{ Sound } \\
\hline Type & Mono \\
\hline
\end{tabular}

ical environments and identify possible obstacles. Also, trials were carried out on video call communication with equipment inside and outside the clinic. Afterward, a consultation was made through a perception survey among the people who participated in the experience, where several of the appreciations were compiled about the robot. 
Cost-benefit relation: The covid-19 pandemic has forced countries to make enormous efforts to try to reduce its spread in the population, especially in the elderly and the health sector community, to such an extent that a study carried out in 73 countries estimated a monthly cost per capita of 8.6 dollars ${ }^{[20]}$, which indicates the large budgets of the countries that have been used to overcome the current crisis. That is why the investment destined in the construction of the robot of 3,500 dollars is beneficial for the health sector since the exposure (of at least 6 people between doctors and nurses per day) to the virus is reduced and therefore the probability of contagion. This means that if the hospital staff rotates every week, and each health worker has at least 1 family member, the number of people with the potential for contagion during a month is 48 . Hence the cost-benefit relationship is 0.117 , which means that it can achieve the return on investment in at least 9 months, which allows deducing the project's viability.

\section{Analysis of robot results as a technical tool in} the hospital: This phase collected all the information. The results obtained were analyzed during the operation of the robot in the hospital environment.

Different actors were tested (medical staff, patients, and technical team), which interacted with the technological tool. The findings found during the pilot test of the robot in the clinic are presented below.

Technical verification of the prototype. The medical assistance simulation sessions developed in the clinic monitored the robot's behavior to determine the technological problems and its functions' performance. Additionally, technical assistance was provided when it was required.
SWOT Matrix. A SWOT matrix as a planning tool is developed to identify the robotic system's potential in the health field. Below is presented the most important aspects found in this process:

\section{- Weaknesses}

The robot has displacement problems because the wheels tend to slip.

The patient in bed is not displayed through the camera of the robot when they are close. This makes it difficult for the doctor to observe the actual state of the patient.

The robot has blind spots for detecting small objects in its environment.

The control of the robot is complex due to the control instrument's operating limitations (keyboard).

There are problems with the connectivity of the robot to the WiFi system of the clinic. The clinic's WiFi network is not optimal. This problem may reflect an inconvenient dependence on communication quality with the institution's infrastructure.

In a noisy environment, the communication of the robot may experience sound-related problems.

Improve the design of the robot to make friendlier interaction with the patient.

The camera seems to have low quality, and the image is not sharp. Including a higher resolution camera might be beneficial, especially for use in inter-consultation. The camera should also be mobile because this favors the peripheral vision of the robotic system. If these aspects are taken into account, it could optimize the robot displacement and improve the patient's visualization. 
To adapt the interface that controls the robot to make the walls, the obstacles, or people's presence more evident.

Driving the robot is difficult with the computer commands. So it is suggested to adopt a device (joystick) to facilitate driving. Another option is using an autonomous displacement system to optimize the time of the medical staff.

- Threats

The spaces for the displacement of the robot in the clinic rooms are reduced, and there are irregular objects of difficult detection.

The WiFi bandwidth of the clinics is limited and only used for basic data management.

There is little experience of the medical staff in the handling of this kind of technological tools.

Ramps or stairs can limit the robot's movement in the corridors of the clinics.

Facilitate the proceeding to make the call with the robot and the inclusion of kin helps to not install another application for communication. Using a link to open a video call is susceptible to possible hacking or communication crossing.

\section{- Strengths}

The sound in both the computer and the robot has good quality when communicating with patients at close range.

The microphone captures well the sound of people in the room because the robot only has to be one meter inside the room to have good communication with the patient.
The robot's remote communication is versatile since both the medical staff and the relatives can communicate with the patient.

The communication between medical staff and patients is good and fluid if there is silence and low traffic on the WiFi network. The people who interacted with the team said they consider it a useful tool for interaction with isolated patients.

\section{- Opportunities}

The increase in the number of infections among medical staff in clinics due to patients' care with COVID 19.

The existence of the SARS-COV-2 virus in closed and confined places such as clinic rooms.

The insufficient number of medical staff to address the health emergency in the country.

Health staff sees a great projection for future use. They believe it is important to be autonomous in the displacement and have a tray to deliver things.

Strategies: The strategies are labored comparing strengths, opportunities, threats, and weaknesses

Successful approach. With the implementation of remote communication employing the robot between the doctor and the patient, it favors medical safety processes related to COVID 19. Bearing in mind that the attention of a patient in a hospital or clinic requires the health staff.

Reaction approach. The robot's reduced size (40 $\mathrm{cm}$ wide, $40 \mathrm{~cm}$ long, and $1.30 \mathrm{~cm}$ high) and the ability to position itself with turns on its center 
facilitate mobility in narrow spaces. It is important to note that hospital and clinic rooms are occupied by multiple objects, furnishings, and equipment.

Adaptive approach. The robot has the function of being used as a tool that virtually brings health staff closer to the patient. To achieve this end, it is imperative to modify the wheels to have more friction with hospital surfaces and to incorporate a camera and screen positioning mechanism to bring the robot as close as possible to the patient.

Survival approach. The robot must be redesigned so that its locomotion module can adapt to sudden changes in environment slopes. There must be another communication option that does not depend on the internet, such as developing local area networks (intranet).

After defining the SWOT matrix and constructing the action strategies, it can deduce that the robotic system has great possibilities of having a positive impact and of becoming a tool of great help for the health staff. To make this impact more effective, it must neutralize the robot's current limitations so that more complex technologies that are less dependent on the hospital infrastructure are incorporated.

\section{Discussion}

After doing a brief search for research projects in the year 2020 related to intelligent and robotic systems applied to the health sector and related to the SARSCOV-2 virus pandemic and of the presentation of the work developed with "GACIPE-MOA20" robot, a comparative analysis of the different projects around their potential in the health sector will be carried out. Francesco et al. ${ }^{[9]}$ presented an Applicative multiagent architecture like a cognitive model, which can interact with patients and physicians in a changing environment and alert or suggest strategies in a given clinical problem. This architecture is evaluated with the Software Architecture Analysis Method (SAAM), establishing that the architecture is modular and can respond adequately to unplanned changes at run time. Geng et al. ${ }^{[10]}$ developing a telerobotic system for remote care in patient rooms in total isolation in hospitals. The research work is focused on the design and development of the robot. The robot has four modules: omnidirectional mobile chassis, double robotic arm, height adjustment mechanisms, and vital signs monitoring devices. The size of the structure of the robot is approximately $60 \mathrm{~cm}$ wide. It is currently under observation in clinical trials. Koppu et al. ${ }^{[11]}$ raised a disease prediction model tested in simulation with the Cleveland and Starlog datasets related to heart disease. The Wisconsin dataset with breast cancer disease is presented.

Francesco et al. ${ }^{[9]}$ and Koppu et al. ${ }^{[11]}$ researches are being carried out on information processing architectures with artificial intelligence methods that allow them to make decisions under the medical body's supervision. However, they are currently being studied through simulations in which they have demonstrated their great power. Geng et al. ${ }^{[10]}$ proposed to develop a robot equipped with technologies for teleoperation and telepresence with multiple functions such as measurement of vital signs (temperature, heart rate), delivery of medicines, and disinfection of parts or containers of SARS-COV-2 (COVID-19). However, its structural dimensions limit those conventional clinic rooms with multiple objects, equipment, and furnishings. In contrast, the robotic system proposed has already been tested in the clinical environment, performing telepresence and telemonitoring operations in regular rooms and the ICU. Despite some difficulties in the operation, it has received good feedback from the medical staff and patients. Considering that clinics and hospitals are common to find rooms with very reduced spaces for displacement, however, in such 
environments, the reduced structure size of the robot (40 cm wide, $40 \mathrm{~cm}$ long, and $1.30 \mathrm{~cm}$ high) has allowed the robot's normal operation without having problems of blockage or jamming. All the above allows us to consider the prototype a viable technological tool to be used in any clinic or hospital to fulfill functions framed in telecommunication and telemonitoring with patients infected with the SARS-COV-2 virus. In general terms, the Health sector is interested in providing robotic systems with significant attributes which allow them to be competitive in their routine procedures.

\section{CONCLUSIONS}

The development of the robot in its different stages of design and implementation with the functions of telepresence and telemonitoring has been consolidated in a short time, leaving the robot at the disposal of the CUB after approximately one month of work.

According to the SWOT matrix analysis and the strategies obtained, it can be possible to say that the robot can become a handy technological tool for health staff as long as the robot's evolution allows them to be independent of the hospital infrastructure. In the aspect of telemonitoring of vital signs, from the beginning, the temperature sensor had some difficulties for the measurement. These were due to the sensor's location that produced defects in the measurement obtained. For the telepresence function, some problems of the robot connectivity with WiFi were found. Also, there were difficulties in the patient's visualization due to the camera's inability to move.

In general terms, there is a positive perception by the medical staff and patients using the robot as a communication and interaction tool in the technical test.

\section{AUTHOR CONTRIBUTIONS}

E.M.R.M. was in charge of the coordination of the construction of the robot; S.C.Z., C.A.V.C., L.T.O. and J.S.T.Z. Mechanical development of the robot; J.E.G.M., J.C.L.L., Y.S.J.M. and J.D.A.P. carried out the electronic development of the robot; P.A.P.C. developed the evaluation and technical diagnosis tools of the robot; J.G.B.G. was in charge of the coordination of the prototype test; E.A.T.S. and V.A.A.U. built the evaluation instruments for the prototype test; B.S.J.F. and J.S.P.Z. developed the prototype tests; V.A.A.T. and Y.A.A.P. developed the analysis of the test results. All authors contributed to the writing of the article.

\section{Ethical statement}

This project focuses solely on describing a robot's implementation and functionality to remotely establish communication between patient and doctor in a simulated way. This work aims to establish the bases (from the technical point of view) of a robot that, in the future, may have uses in those patients who suffer from infectious diseases such as Covid-19. 


\section{REFERENCES}

[1] González-Jaramillo V, González-Jaramillo N, Gómez-Restrepo C, et al. Impact of the COVID-19 pandemic on the Colombian population according to mitigation measures. Preliminary data from epidemiological models for the period March 18 to April 18. Rev Sal Pub [Internet]. 2020;22(2):1-6. Available from: https://doi.org/10.15446/rsap.v22n2.85789

[2] Sanchez-Duque JA, Orozco-Hernandez JP, Marin-Medina DS, Arteaga-Livias K, et al. Economy or Health, Constant Dilemma in Times of Pandemic: The case of Coronavirus Disease 2019 (COVID19). J Pure Appl Microbiol [Internet]. 2020;14(suppl 1):717-720. Available from: https://doi.org/10.22207/JPAM.14.SPL1.07

[3] Acter T, Uddin N, Das J, Akhter A, et al. Evolution of severe acute respiratory syndrome coronavirus 2 (SARS-CoV-2) as coronavirus disease 2019 (COVID-19) pandemic: A global health emergency. Sci Total Environ [Internet]. 2020;730:138996. Available from: https://doi.org/10.1016/i.scitotenv.2020.138996

[4] Climent-Ballester S, Selva-Otaolaurruchi J. Hospital Pharmacy: Comprehensive management of medical devices during SARSCoV-2. Farm Hosp [Internet]. 2020;44(7):21-23. Available from: https://doi.org/10.7399/fh.11486

[5] Jiang Q, Liu Y, Wei W, Chen A, et al. The Incidence and Epidemic Characteristics of Medical Staff's Skin Injuries Caused by Personal Protective Equipment for Fighting against SARS-CoV-2 Infection. Chinese Gen Pract. 2020;23(9):1083 - 1090.

[6] Rolim Neto ML, Gomes Almeida HG, D'arc Esmeraldo J, et al. When health professionals look death in the eye: the mental health of professionals who deal daily with the 2019 coronavirus outbreak. Psychiatry Res [Internet]. 2020;288:112972. Available from: https://doi.org/10.1016/j.psychres.2020.112972

[7] Jin YH, Huang Q, Wang YY, et al. Perceived infection transmission routes, infection control practices, psychosocial changes, and management of COVID-19 infected healthcare workers in a tertiary acute care hospital in Wuhan: A cross-sectional survey. Military Med Res [Internet]. 2020;7. Available from: https://doi.org/10.1186/s40779-020-00254-8

[8] Győrffy Z, Békási S, Szathmári-Mészáros N, Németh O. Possibilities of telemedicine regarding the COVID-19 pandemic in light of the international and Hungarian experiences and recommendations. Orv Hetilap [Internet]. 2020;161(24):983-992. Hungarian. Available from: https://doi.org/10.1556/650.2020.31873

[9] Lanza F, Seidita V, Chella A. Agents and robots for collaborating and supporting physicians in healthcare scenarios. J Biomed Inform [Internet]. 2020;108:103483. Available from: https://doi.org/10.1016/j.jbi.2020.103483

[10] Yang G, Lv H, Zhang Z, et al. Keep Healthcare Workers Safe: Application of Teleoperated Robot in Isolation Ward for COVID-19 Prevention and Control. Chin J Mech Eng [Internet]. 2020;33:47(2020). Available from: https://doi.org/10.1186/s10033-020-00464-0
[11] Koppu S, Maddikunta PKR, Srivastava G. Deep learning disease prediction model for use with intelligent robots. Comput Electr Eng [Internet]. 2020;87:106765. Available from: https://doi.org/10.1016/i.compeleceng.2020.106765

[12] Farah S, Anderson DG, Langer R. Physical and mechanical properties of PLA, and their functions in widespread applications A comprehensive review. Adv Drug Deliv Rev [Internet]. 2016;107:367-392. Available from: https://doi.org/10.1016/j.addr.2016.06.012

[13] Zhang YL, Velinsky SA, Feng X. On the Tracking Control of Differentially Steered Wheeled Mobile Robots. J Dyn Syst Meas Control [Internet]. 1997;119(3):455-461. Available from: https://doi.org/10.1115/1.2801278

[14] Muir PF, Neuman CP. Kinematic modeling of wheeled mobile robots. J Robot Syst [Internet]. 1987; 4(2):281-340. Available from: https://doi.org/10.1002/rob.4620040209

[15] Li Y, Dai S, Zheng Y, et al. Modeling and Kinematics Simulation of a Mecanum Wheel Platform in RecurDyn. J Robot [Internet]. 2018; 2018:9373580. Available from: https://doi.org/10.1155/2018/9373580

[16] Zhang S, Gao J, Duan X, et al. Trot pattern generation for quadruped robot based on the ZMP stability margin. In 2013 ICME International Conference on Complex Medical Engineering [Internet]. Beijing: IEEE; 2013:608-613. Available from: https://doi.org/10.1109/ICCME.2013.6548322

[17] Rico Mesa EM, Hernandez-Riveros J-A. Handling the Transition in the Locomotion of an Articulated Quadruped Robot by Adaptive CPG. IAENG Int J Comput Sci. 2020;47(4):792-804.

[18] Sugano S, Huang Q, Kato I. Stability criteria in controlling mobile robotic systems. In Proceedings of 1993 IEEE/RSJ International Conference on Intelligent Robots and Systems (IROS '93) [Internet]. Yokohama: IEEE; 2002: 832-838. Available from: https://doi.org/10.1109/IROS.1993.583186

[19] Kim J, Chung WK. Real-time zero moment point compensation method using null motion for mobile manipulators. Adv Robot [Internet]. 2006;20(5): 581-593. Available from: https://doi.org/10.1163/156855306776985586

[20] Tan-Torres Edejer T, Hanssen O, Mirelman A, et al. Projected healthcare resource needs for an effective response to COVID-19 in 73 lowincome and middle-income countries: a modelling study. Lancet Glob Health [Internet]. 2020;8(11): e1372 - e1379. Available from: https://doi.org/10.1016/S2214-109X(20)30383-1 